\title{
Phytomedicine
}

Phytomedicine 16 (2009) 960-966

www.elsevier.de/phymed

\section{In vitro anti-herpetic activity of an aqueous extract from the plant Phyllanthus orbicularis}

\author{
Ángel L. Álvarez", Gloria del Barrio ${ }^{\mathrm{a}}$, Vivian Kourí ${ }^{\mathrm{b}}$, Pedro A. Martínez ${ }^{\mathrm{b}}$, \\ Belén Suárez ${ }^{c}$, Francisco Parra ${ }^{\mathrm{d}, *}$ \\ ${ }^{a}$ Departamento de Microbiología y Virología, Facultad de Biología, Universidad de La Habana, La Habana, Cuba \\ ${ }^{\mathrm{b}}$ Departamento de Virología, Instituto de Medicina Tropical Pedro Kourí, La Habana, Cuba \\ 'Área de Tecnología de los Alimentos, Servicio Regional de Investigación y Desarrollo Agroalimentario (SERIDA), Asturias, Spain \\ ${ }^{\mathrm{d}}$ Instituto Universitario de Biotecnología de Asturias, Departamento de Bioquímica y Biología Molecular, Edificio Santiago Gascón, \\ Campus El Cristo, Universidad de Oviedo, 33006 Oviedo, Asturias, Spain
}

\begin{abstract}
The Herpesviridae includes at least eight viral species pathogenic for humans, responsible for a wide variety of clinical symptoms. The lack of an effective vaccine and the moderate to high toxicity of the available synthetic antiherpes compounds emphasises the need for new inhibitors. Several Phyllanthus genus (Euphorbiaceae) members have been widely used in traditional medicine and their biological properties have been intensely studied. In this study we investigated the in vitro antiviral activity of the Cuban-endemic plant Phyllanthus orbicularis H.B.K. against Herpes simplex virus type 1 (HSV-1) and 2 (HSV-2) reference strains and clinical isolates with different sensitivities to acyclovir. The inhibitory activity on Human cytomegalovirus (HCMV) replication was also investigated. The selectivity indexes (SI) found for Ph. orbicularis aqueous extract ranged from 8.7 to 37.6. Studies on the antiviral mechanisms involved revealed that the drug acted at early stages of herpesvirus replication, possibly by producing a virucidal effect, although further inhibition of intracellular replication events could not be ruled out.
\end{abstract}

(C) 2009 Elsevier GmbH. All rights reserved.

Keywords: Phyllanthus; HSV; Cytomegalovirus; Ethnomedicine; Antiviral

\section{Introduction}

The family Herpesviridae comprises at least eight species of enveloped viruses, with linear doubledstranded DNA genomes, which are pathogenic for humans. Herpes simplex viruses (HSV-1 and HSV-2) stand out because of the wide variety of clinical symptoms they provoke, including oral and genital vesicular lesions, keratoconjunctivitis, eczema, encephalitis, pneumonia and hepatitis (Rajcani and Durmanova

${ }^{*}$ Corresponding author. Tel.: + 34985103563 ; fax: +34985103157 .

E-mail address: fparra@uniovi.es (F. Parra).
2001; Whitley et al. 1998). Primary infection by Human cytomegalovirus (HCMV), a member of the Betaherpesvirinae subfamily, is particularly relevant for pregnant women whose foetuses are at risk of congenital malformations and death due to the teratogenic attributes of this virus. In addition, HCMV has been identified as having a role in organ rejection among transplant recipients and retinitis in AIDS patients (Ljungman 2002; Taylor 2003).

The relatively high toxicity of synthetic antiherpetic compounds and the continuous spread of drug-resistant viral strains emphasise the need for new antiviral products. Several plants of the genus Phyllanthus 
(Euphorbiaceae) have been intensely studied and their antiviral activity against hepadnaviruses and human immunodeficiency virus type 1 (HIV-1) have been conclusively proved (Notka et al. 2004; Ogata et al. 1992; Venkateswaran et al. 1987). The Cuban endemic species Phyllanthus orbicularis H.B.K., widely used in Cuban folk medicine, has also been investigated and its anti-hepatitis B virus activity was confirmed (del Barrio et al. 1995). In addition, we communicated the antiviral activity of this plant against HSV-1, HSV-2 and bovine herpesvirus-1 (BHV-1) (subfamily Alphaherpesvirinae) (del Barrio and Parra 2000; Fernandez-Romero et al. 2003).

In the study presented here we have investigated the anti-HSV activity of an aqueous extract from $P$. orbicularis using a panel of herpesviruses including acyclovir (ACV)-resistant and sensitive clinical isolates together with laboratory strains of HSV-1 and HSV-2. Furthermore we have evaluated the inhibitory activity of this particular Phyllanthus species against HCMV, a member of Betaherpesvirinae subfamily.

\section{Materials and methods}

\section{Plant extract}

Phyllanthus orbicularis plants were collected in the region of Cajálbana, Pinar del Río (Cuba). A voucher specimen was delivered to the National Botanical Garden of Cuba (herbarium number: 7-220-HAJB) and authenticated by Dr. Rosalina Berazaín, a researcher from that institution. The aqueous extract used in this work was prepared and lyophilized as previously described (del Barrio and Parra 2000). Briefly, the plant stem and leaves were dried at $50{ }^{\circ} \mathrm{C}$ for three days, before grinding. The ground material $(100 \mathrm{~g})$ was suspended 1:10 (w/v) in distilled water, and shaken for $4 \mathrm{~h}$ in a water bath at $70^{\circ} \mathrm{C}$. The resulting suspension was filtered and the filtrate centrifuged at 10000 r.p.m. using a JA-10 rotor in a Beckman JA-21 centrifuge. The supernatant was lyophilised for further use.

\section{Viruses and cells}

HSV-1 reference strains F, 8WT and 8ACV, as well as HSV-1 and HSV-2 clinical isolates with different susceptibilities to acyclovir (ACV), and HCMV reference strain AD169, were all obtained from the Viral STDs Diagnosis Laboratory, Institute of Tropical Medicine Pedro Kourí. HSV-1 and HSV-2 were propagated in African green monkey kidney (Vero) cells (ATCC CCL-81) and their susceptibilities to ACV were previously tested in our lab, according to the methodology described by Estevez et al. (1991) (data not shown). HCMV AD169 strain was propagated using a human embryonic lung (HEL) fibroblast diploid cell line (subculture number 16). Virus titrations were performed using the endpoint dilution method described by Reed and Muench (1938). Vero cells were propagated in medium 199 (Gibco BRL) supplemented with 5\% foetal bovine serum (Sigma). HEL cells were propagated in Eagle's minimal essential medium (Gibco BRL) supplemented with $10 \%$ foetal bovine serum. Both cell lines were maintained in the previously mentioned media with serum concentrations reduced to $2 \%$.

\section{Cytotoxicity assays}

Vero and HEL cells were seeded into 96-well plates at a density of $2 \times 10^{4}$ cells/well, and incubated at $37^{\circ} \mathrm{C}$ in a $5 \% \mathrm{CO}_{2}$ atmosphere for $48-72 \mathrm{~h}$, until $90 \%$ or greater confluence of the monolayers was reached. Increasing concentrations of the test plant extract ranging from 10 to $1500 \mu \mathrm{g} / \mathrm{ml}$ were added to cells, with a replicate number of six wells per concentration. Vero and HEL cells were incubated in the above-mentioned conditions with the test extract for 3 or 7 days, respectively. After the incubation period, a 3-(4,5-dimethylthiazol-2-yl)2,5-diphenyl tetrazolium bromide (MTT) solution was added to the cells (final concentration $0.5 \mathrm{mg} / \mathrm{ml}$ ) and the plates were incubated for another $4 \mathrm{~h}$ to allow formazan production. The solid precipitate was dissolved with dimethylsulphoxide (Sigma) and the absorbance at $570 \mathrm{~nm}$ was measured using a MRX Revelation Spectrophotometer (Dynex Technologies ${ }^{\circledR}$ ) with a reference wavelength of $620 \mathrm{~nm}$. The resulting cell viability was calculated as described by Mosmann (1983).

\section{Antiviral assays}

Ninety-six-well plates containing confluent cell monolayers were preincubated for $1 \mathrm{~h}$ with increasing noncytotoxic concentrations of the plant extract in the range of 10 to $100 \mu \mathrm{g} / \mathrm{ml}$. Six wells were used for each concentration. Afterwards, $10 \mathrm{TCID}_{50}$ of HSV-1 or HSV-2, or $25 \mathrm{TCID}_{50}$ of HCMV were added into each well. Plates were incubated at $37^{\circ} \mathrm{C}$ in a $5 \% \mathrm{CO}_{2}$ atmosphere and observed daily for CPE using a light microscope. When CPE was observed in all virus control wells, the percentage of wells with CPE was determined for each treatment concentration. Acyclovir (ACV) at concentrations varying from 0.5 to $6 \mu \mathrm{g} / \mathrm{ml}$ served as positive controls, in anti-HSV assays.

\section{Time-of-addition experiment}

The effect of the plant extract on HSV yields when added to cell cultures at different times before, at or 
after infection was investigated as described previously (Fernandez-Romero et al. 2003), with minor modifications. Vero cells were seeded in 24 -well plates at a density of $2 \times 10^{5}$ cells/well and incubated for $48 \mathrm{~h}$. The aqueous extract of $P$. orbicularis was then added to the first series of wells at a fixed non-cytotoxic concentration of $150 \mu \mathrm{g} / \mathrm{ml}$, and incubated additionally for $1 \mathrm{~h}$. All wells in the plate were then infected with 200 TCID $_{50}$ of HSV-1 or HSV-2 and the same concentration of extract was added to the second series of wells at the time of infection. Subsequent additions were performed $45 \mathrm{~min}, 1.5$ and $5.5 \mathrm{~h}$ post-infection (h.p.i.). When $100 \%$ CPE in untreated virus wells was recorded the plate was freeze-thawed three times. The content of each well was centrifuged at $1500 \mathrm{~g}$ for $15 \mathrm{~min}$ and the infective titre of the culture supernatants was determined as previously described (Reed and Muench 1938).

\section{Virucidal assays}

Viral suspensions of each strain of HSV-1, HSV-2 and HCMV were mixed with identical volumes of the plant extract or the equivalent quantity of culture medium (negative control) and then incubated at $26^{\circ} \mathrm{C}$ or $37^{\circ} \mathrm{C}$ for 0.5 or $3 \mathrm{~h}$. The residual virus infectivity was investigated as described elsewhere (Reed and Muench 1938). Three different concentrations of the extract were assayed in duplicate.

\section{Quantitative real-time polymerase chain reaction assay for HCMV}

HEL cells were seeded in 24-well plates at a density of $2 \times 10^{5}$ cells/well and incubated for $72 \mathrm{~h}$. Each well was infected with 200 TCID $_{50}$ of the AD169 strain and the plate was centrifuged at $1000 \mathrm{~g}$ for $30 \mathrm{~min}$ in an ALC-PM140R centrifuge. Virus attachment was allowed to continue for an additional $30 \mathrm{~min}$ incubation at $37^{\circ} \mathrm{C}$. Supernatants were discarded and the cell monolayers gently washed with PBS to remove unattached virions. Fresh maintenance medium with noncytotoxic concentrations of the plant extract were added into the infected wells. When $80 \%$ or greater CPE was observed in virus control wells, $200 \mu \mathrm{l}$ of supernatant of each treated-infected, untreated-infected (virus control) and mock-infected wells were collected. DNA extraction from these supernatants was performed using QIAamp Mini Kit (QIAGEN) following the manufacturer specifications. Real time PCR quantification of viral DNA was accomplished using the Artus ${ }^{\circledR}$ CMV LC PCR Kit (QIAGEN) in a LightCycler 1.5 apparatus (ROCHE Diagnostics). The specifications and running program were used as recommended by the manufacturer. DNA concentrations were calculated by extrapolation from an imported standard curve, previously built using the included kit standards.

\section{Reversed-phase high performance liquid chromatography (HPLC) analysis}

HPLC analysis was performed according to a previously described method (Suárez et al. 2005) using a Waters system equipped with a 717 automatic injector, a column oven, two pumps (model 510), a diode array detector (model 2996) and the Empower 2 software data module. Separation of polyphenols was carried out on a reversed-phase Nucleosil $120 \mathrm{C}_{18}(250 \times 4.6 \mathrm{~mm}$ I.D, $3 \mu \mathrm{m}$ ) column (Teknokroma, Barcelona, Spain) at $30^{\circ} \mathrm{C}$, using a flow rate of $0.8 \mathrm{ml} / \mathrm{min}$. The elution solvents were aqueous $2 \%$ acetic acid (solvent $\mathrm{A}$ ) and $100 \%$ methanol (solvent B). The samples were eluted according to the following program: a linear gradient from $0 \%$ to $45 \%$ of solvent $\mathrm{B}$ in $55 \mathrm{~min}$ and a final isocratic step of $20 \mathrm{~min}$. Ten microlitres of Ph. orbicularis aqueous extract were injected after filtration through a $0.22 \mu \mathrm{m}$ PVDF membrane (Millipore). Absorbance measurements were performed at $313 \mathrm{~nm}$ for the hydroxycinnamic acids, $355 \mathrm{~nm}$ for the flavonol glycosides and $280 \mathrm{~nm}$ for the rest of phenolic compounds.

\section{Statistics}

The mean cytotoxic concentration $\left(\mathrm{CC}_{50}\right)$ and antiviral effective concentration $\left(\mathrm{EC}_{50}\right)$ values were calculated by regression analysis using the dose-response curves generated from the experimental data. All results, except those related to HCMV, are presented as the mean values and standard deviations from three independent experiments. A selectivity index (SI) was calculated for each viral strain by dividing the $\mathrm{CC}_{50}$ by the $\mathrm{EC}_{50}$ value. SI values as well as the reduction indexes of viral titres in virucidal assays with HSV-1 and HSV-2 were compared using ANOVA, followed by Tukey's multiple mean comparison tests. The Student's unpaired t-test was used to compare virucidal activities at different temperatures and incubation times. Values of $p<0.05$ were considered indicative of statistical differences.

\section{Results and Discussion}

\section{Cytotoxic effects and anti-HSV activity of $\boldsymbol{P h}$. orbicularis}

In order to assess the cytotoxic effects of the $P h$. orbicularis aqueous extract a colorimetric MTT assay was performed after incubating cell cultures 
with increasing concentrations of the plant extract (Mosmann 1983). The $\mathrm{CC}_{50}$ values obtained for Vero or HEL cells were $1082.8 \pm 98.9 \mu \mathrm{g} / \mathrm{ml}$ and $504.19 \pm 8.32 \mu \mathrm{g} / \mathrm{mL}$, respectively. These values correlated well with morphological changes such as cell rounding, the presence of cytoplasmic inclusions and loss of monolayer confluence, recorded during microscopic examination of treated cultures. These changes became evident from extract concentrations at or above $700 \mu \mathrm{g} / \mathrm{ml}$ in Vero and $300 \mu \mathrm{g} / \mathrm{mL}$ in HEL cells. At $100 \mu \mathrm{g} / \mathrm{ml}$, the highest concentration used in antiviral assays, the mean cell viability was close to $100 \%$ in Vero cells and to $80 \%$ in HEL cells (data not shown).

The proliferation in cell culture of all HSV-1 and HSV-2 strains and clinical isolates included in this study was significantly inhibited by the Ph. orbicularis aqueous extract which was able to reduce the virusinduced CPE on Vero cells by more than $50 \%$. SI values for the aqueous plant extract assayed against HSV ranged from 13.3 to 37.6 (Table 1) and no significant differences were found between the assayed HSV strains, except those observed for HSV-1 reference strains F, 8WT and 8ACV whose sensitivities to the $P h$. orbicularis extract was higher than those of the clinical isolates (Table 1). In agreement with previously published data, the extent of inhibition observed was not related to virus resistance or sensitivity against ACV (Fernandez-Romero et al. 2003). The ACV EC $\mathrm{E}_{50}$ values obtained were $2.8 \mu \mathrm{g} / \mathrm{ml}$ for $\mathrm{HSV}-1$ strain $8 \mathrm{ACV}$, previously described as ACV-resistant; $1.2 \mu \mathrm{g} / \mathrm{ml}$ for the ACV-sensitive HSV-1 strain 2677, and $5.1 \mu \mathrm{g} / \mathrm{ml}$ for the ACV-resistant HSV-2 clinical isolate 2373. It should be mentioned that an $\mathrm{EC}_{50}$ value of $2 \mu \mathrm{g} / \mathrm{ml}$ or greater, is considered as indicative of ACV resistance of a HSV strain, as has been previously reported (Stranska et al. 2002).

\section{Studies on the mechanism of action of Ph. orbicularis on HSV replication}

A time-of-addition experiment was performed to investigate the stage of HSV replication cycle, putatively inhibited by the plant extract. The strongest HSV proliferation inhibition was achieved when the extract was added before or during the initial stages of infection. Ph. orbicularis targeted HSV early replication events, since the plant extract is much less effective if added after 2 h.p.i.; however a residual inhibition could be detected during the course of study (Fig. 1). These

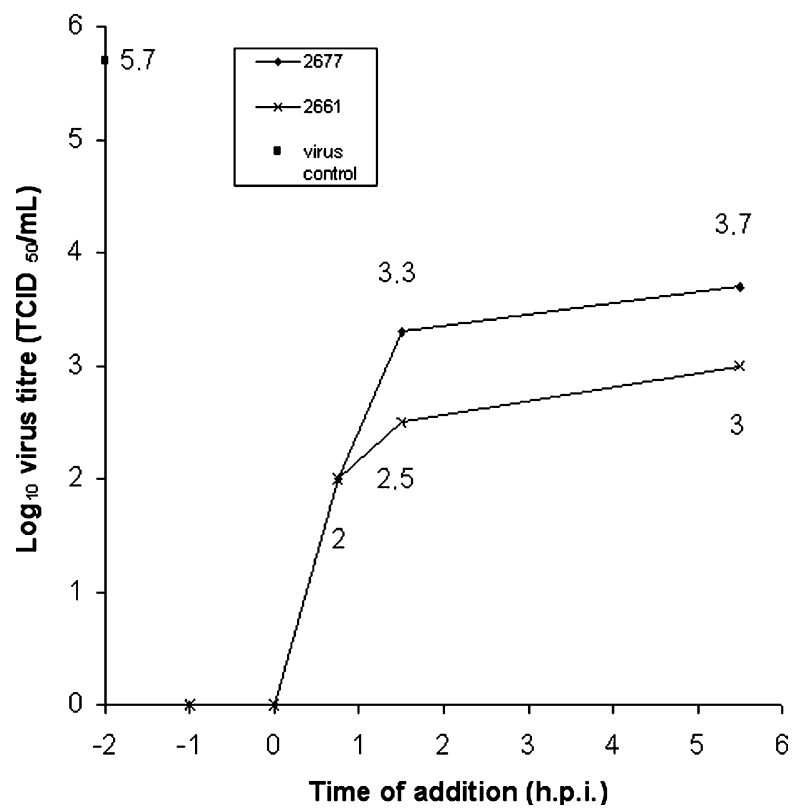

Fig. 1. Effect of Ph. orbicularis aqueous extracts on HSV-1 (2677) and HSV-2 (2661) yields when added to cell cultures at different times: $1 \mathrm{~h}$ before infection, during infection and $45 \mathrm{~min}, 90 \mathrm{~min}$ or 5.5 h.p.i.

Table 1. Antiviral activity of the Ph. orbicularis aqueous extract against HSV strains with known sensitivities to ACV, and AD169 HCMV strain.

\begin{tabular}{|c|c|c|c|c|c|c|c|}
\hline Cells & $\mathrm{CC}_{50}(\mu \mathrm{g} / \mathrm{ml})$ & Virus species & Strain & Sensitivity to ACV & $\mathrm{EC}_{50}(\mu \mathrm{g} / \mathrm{ml})$ & SI & $\S$ \\
\hline \multirow[t]{8}{*}{ Vero } & $1082.8 \pm 98.9$ & HSV-1 & $8 \mathrm{WT}$ & Sensitive & $34.3 \pm 1.2$ & 31.6 & $a b$ \\
\hline & & & $8 \mathrm{ACV}$ & Resistant & $39.39 \pm 6.5$ & 27.5 & $a b$ \\
\hline & & & $\mathrm{F}$ & Sensitive & $28.80 \pm 9.24$ & 37.6 & $\mathrm{a}$ \\
\hline & & & 2677 & Sensitive & $63.47 \pm 10.7$ & 17.0 & $\mathrm{~b}$ \\
\hline & & & 2463 & Unknown & $62.95 \pm 6.15$ & 17.2 & $\mathrm{~b}$ \\
\hline & & HSV-2 & SA & Resistant & $81.65 \pm 9.16$ & 13.3 & $\mathrm{~b}$ \\
\hline & & & 2661 & Resistant & $75.47 \pm 8.47$ & 14.3 & $\mathrm{~b}$ \\
\hline & & & 2373 & Resistant & $57.82 \pm 9.45$ & 18.7 & $\mathrm{~b}$ \\
\hline HEL & $504.19 \pm 8.32$ & HCMV & AD169 & - & 57.7 & 8.7 & - \\
\hline
\end{tabular}

$\S:$ Tukey's means multiple comparison test indexes applied to SI values.

Data are presented as the mean values of three independent experiments including their standard deviations (except those related to AD169). 
results are consistent with studies on the antiviral activity of this and other plant extracts (Cheng et al. 2004; del Barrio and Parra 2000; Felipe et al. 2006). As this may have been due to the ability of some constituents present in the aqueous extract to directly inactivate viral particles, we carried out virucidal assays. The incubation of virus suspensions with three different concentrations of the plant extract for $3 \mathrm{~h}$ at $37^{\circ} \mathrm{C}$ drastically diminished viral infectivity, independent of the HSV isolate, HSV type or its ACV sensitivity (Fig. 2A). In all cases the virucidal values found were dose-dependent. No significant differences $(p>0.05)$ in virion inactivation titres were found when the virus suspensions were treated with the plant extract at $26^{\circ} \mathrm{C}$ or $37^{\circ} \mathrm{C}$ for periods ranging from $30 \mathrm{~min}$ to $3 \mathrm{~h}$ (Figs. $2 \mathrm{~B}$ and $\mathrm{C}$ ). In all cases, the virus titre reduction was greater than $1 \log _{10}$, indicating a strong inactivating activity, equivalent to $90 \%$ inactivation of the treated virions ( $\mathrm{Hu}$ and Hsiung 1989). In most cases the reduction exceeded $2 \log _{10}$ units, indicating that more than $99 \%$ of the viral particles were inactivated by the treatment $(\mathrm{Hu}$ and Hsiung 1989). Although the virucidal effect appeared to be the main component of the antiviral properties of this plant, partially-purified water-soluble polyphenolic compounds isolated from this Phyllantus species have also been found to be responsible for a different inhibitory activity acting at the viral penetration stage (manuscript on preparation).

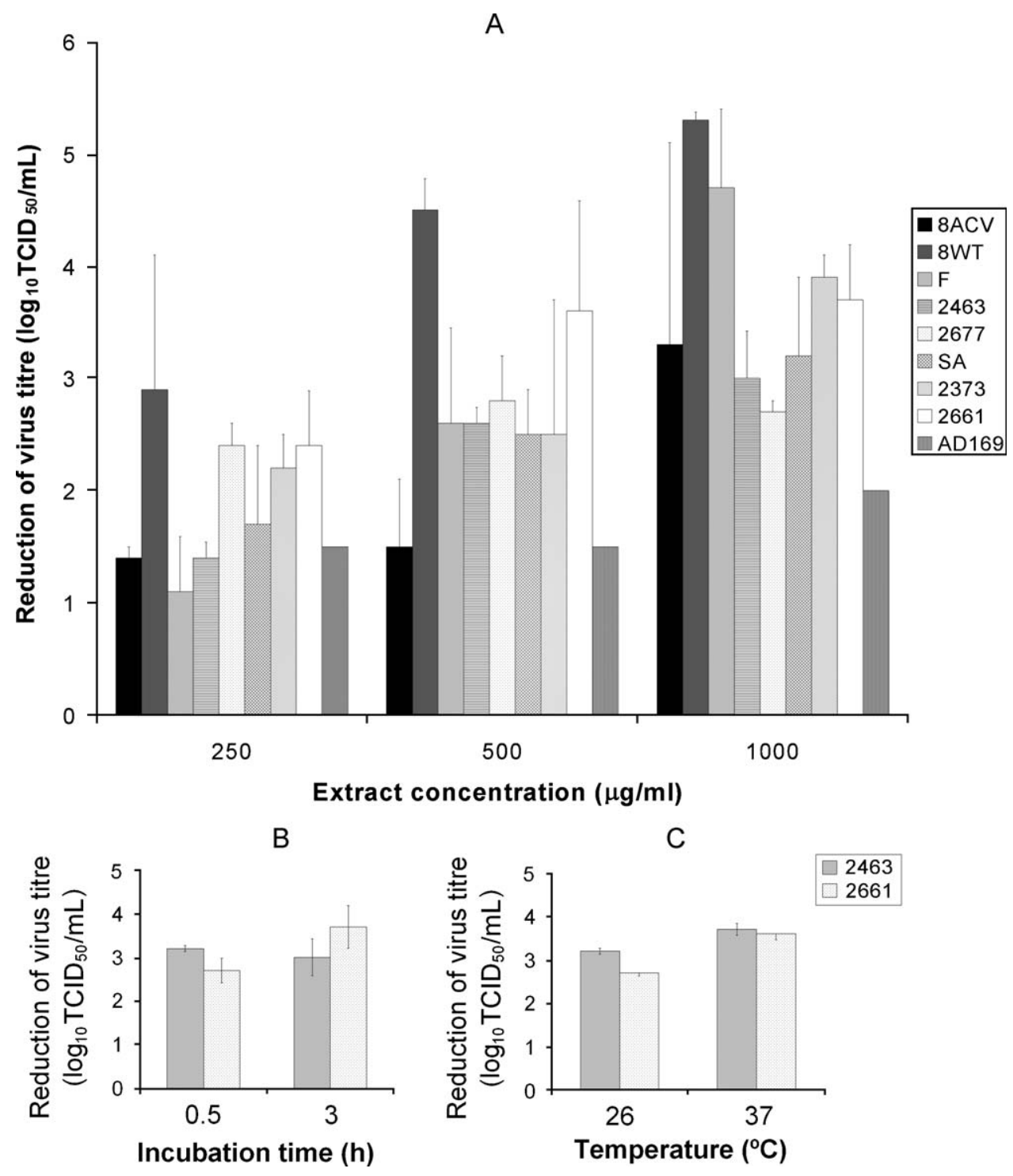

Fig. 2. Virucidal activity of $P$. orbicularis aqueous extract against several strains of HSV-1, HSV-2 and HCMV strain AD169 (A). Influence of exposure time (B) and temperature (C) on HSV-1 (2463) and HSV-2 (2661) using 500 $\mu \mathrm{g} / \mathrm{ml}$ of plant extract. Data are presented as the mean of three independent experiments including their standard deviation values. The AD169 data correspond to a single experiment. 


\section{Anti-HCMV activity of $P h$. orbicularis}

Our initial studies on the inhibitory activity of $P h$. orbicularis aqueous extract against the betaherpesvirus HCMV showed a SI value of 8.7 (Table 1). It was observed that the morphological alterations of HEL cells due to replication of HCMV strain AD169 were completely prevented when $100 \mu \mathrm{g} / \mathrm{ml}$ of the plant extract were present in infected cultures (data not shown).

Although the $P h$. orbicularis extract $\mathrm{EC}_{50}$ value against HCMV was similar to those found for HSV, the slow replication rate of HCMV in fibroblast cultures required cytotoxicity analyses for longer culture times with the consequent decrease in cell viability and $\mathrm{CC}_{50}$ value, thus yielding comparatively lower selectivity indexes (SI).

The HCMV virion-inactivating activity of this plant extract was also demonstrated although to a lesser extent in comparison with the effects on the HSV strains. A reduction of AD169 titres of more than $1 \log _{10}$ was found for all the assayed plant extract concentrations (Fig. 2A).

The in vitro inhibitory activity of Ph. orbicularis extract on HCMV intracellular replication events was assessed by measuring the viral DNA yields in infected culture supernatants, by means of a real-time PCR assay. The plant extract was added after virus adsorption and was present in the culture medium until the end of the experiment. The curves generated during PCR reactions show a prominent drop in HCMV DNA amounts in treated cultures when compared to those of virus controls (Fig. 3). The calculated viral DNA concentrations in cultures treated with $10 \mu \mathrm{g} / \mathrm{ml}$ and $25 \mu \mathrm{g} / \mathrm{mL}$ of the Phyllantus extract were $2.883 \times 10^{6}$ and $2.721 \times 10^{6}$ copies $/ \mathrm{ml}$ respectively, 5 -fold lower than the viral DNA present in the untreated

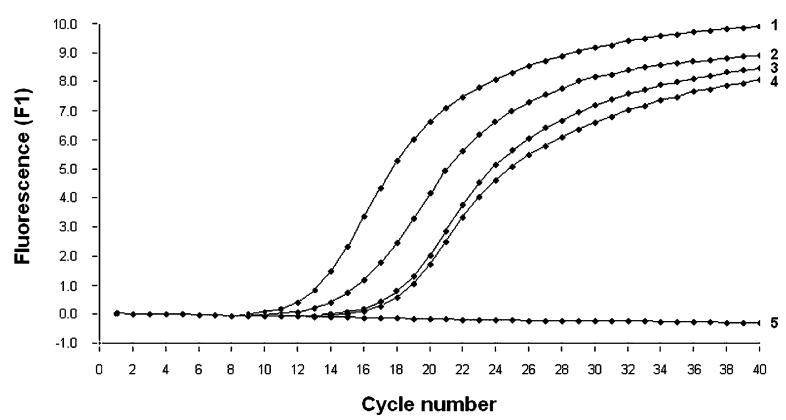

Fig. 3. Effect of the Ph. orbicularis aqueous extract on HCMV DNA concentrations in infected HEL culture supernatants as determined by real-time PCR. (1) Infected non-treated culture (virus control); (2) standard reaction containing $10^{4}$ copies $/ \mu 1$ of HCMV DNA; (3) infected culture treated with $10 \mu \mathrm{g} / \mathrm{ml}$ of the plant extract; (4) infected culture treated with $25 \mu \mathrm{g} / \mathrm{ml}$ of the plant extract; (5) mock-infected cell culture. virus control $\left(1.501 \times 10^{7}\right.$ copies $\left./ \mathrm{ml}\right)$. No HCMV DNA was detected in mock-infected cells. Whether $P h$. orbicularis inhibited events prior to viral DNA synthesis (immediate-early and early replication stages) or DNA synthesis itself, remain to be elucidated. This is the first report of antiviral activity of a species from the Phyllanthus genus against a member of Betaherpesviridae subfamily.

\section{Liquid chromatography analysis of $\boldsymbol{P h}$. orbicularis water extract}

In order to determine the families of compounds and major constituents present in Ph. orbicularis water extract a HPLC analysis was performed. The main peaks were assigned to families or compounds by comparing its UV-visible spectra and retention times with those of standards and by HPLC analysis of mixtures containing sample plus each available standard. The predominant phenolic families detected were quercetin glycosides, flavanols, condensed tannins (procyanidin dimers) and gallic acid-derivatives. Quercetin3-O-rutinoside (rutin), kaempherol-3-O-rutinoside, procyanidin $\mathrm{B} 1$, procyanidin $\mathrm{B} 2$, catechin, epicatechin, and protocatechuic acid were identified in the extract (Fig. 4). Further isolation procedures are being carried out in order to investigate whether a unique molecule among these or its interaction with the rest of compounds contribute to the recorded antiviral effect.

$P h$. orbicularis is a potential source of interesting antiHCMV and anti-HSV leader compounds for the pharmacological industry, especially when many drugresistant mutants of these viruses are being reported. In addition, the virucidal properties found suggest its potential for use in topical formulations to treat the widespread dermatological lesions caused by HSV.

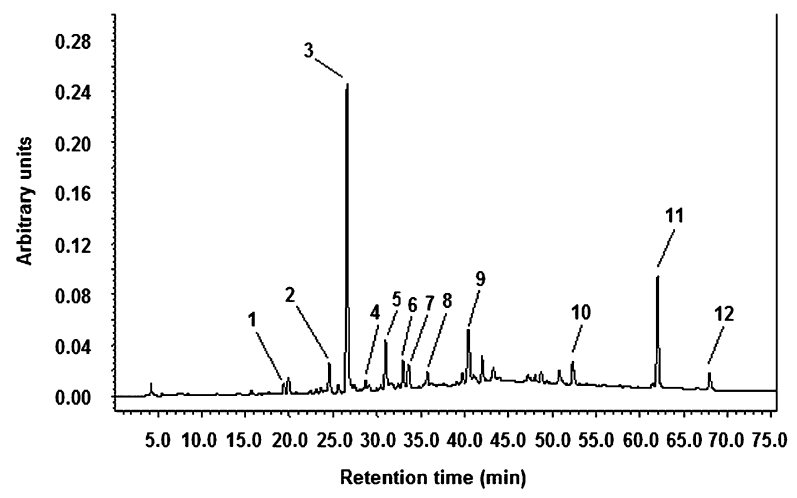

Fig. 4. Reversed-phase HPLC fingerprint of Ph. orbicularis aqueous extract recorded at $280 \mathrm{~nm}$. (1) protocatechuic acid; (2), (3), (6) and (7) unknown flavanols; (4) procyanidin B1; (5) catechin; (8) procyanidin B2; (9) epicatechin; (10) unknown gallic acid-derivative; (11) quercetin-3-O-rutinoside; (12) kaempherol-3-O-rutinoside. 


\section{Acknowledgements}

The authors are very grateful to Dianeya Mendoza, Yamira Caballero, Luis Morier (Cell Culture Department, Pedro Kourí Institute of Tropical Medicine) and Maikel Acosta (Faculty of Biology, University of Havana) for their technical assistance in cell culture seeding and cytotoxicity assays. We also thank to Kevin P. Dalton (University of Oviedo) for critical revising of the manuscript. This work was partially funded by the Ayuntamiento de Gijón, the University of Oviedo (Asturias, Spain) and the Pedro Kouri Institute of Tropical Medicine (Havana, Cuba).

\section{References}

Cheng, H.Y., Lin, T.C., Yang, C.M., Wang, K.C., Lin, L.T., Lin, C.C., 2004. Putranjivain A from Euphorbia jolkini inhibits both virus entry and late stage replication of herpes simplex virus type 2 in vitro. J. Antimicrob. Chemother. 53, 577-583.

del Barrio, G., Caballero, O., Chevalier, P., 1995. Inactivación in vitro del AgsHB por extractos de plantas del género Phyllanthus. Rev. Cubana Med. Trop. 47, 127-130.

del Barrio, G., Parra, F., 2000. Evaluation of the antiviral activity of an aqueous extract from Phyllanthus orbicularis. J. Ethnopharmacol. 72, 317-322.

Estevez, D., Castellanos, A., Rodriguez, C., Tenorio, A., 1991. Decrease in HSV titres in the presence of acyclovir and foscarnet: a simple method for screening of antiviral resistance. Third Joint Meeting of the European Group for Rapid Viral Diagnosis and the European Society Against Virus Diseases, Strasbourg, France.

Felipe, A.M., Rincao, V.P., Benati, F.J., Linhares, R.E., Galina, K.J., de Toledo, C.E., Lopes, G.C., de Mello, J.C., Nozawa, C., 2006. Antiviral effect of Guazuma ulmifolia and Stryphnodendron adstringens on poliovirus and bovine herpesvirus. Biol. Pharm. Bull. 29, 1092-1095.
Fernandez-Romero, J.A., del Barrio, G., Romeu, B., Gutierrez, Y., Valdes, S., Parra, F., 2003. In vitro antiviral activity of Phyllanthus orbicularis extracts against herpes simplex virus type 1. Phytother. Res. 17, 980-982.

Hu, J.M., Hsiung, G.D., 1989. Evaluation of new antiviral agents: I. In vitro perspectives. Antiviral Res. 11, 217-232.

Ljungman, P., 2002. Beta-herpesvirus challenges in the transplant recipient. J. Infect. Dis. 186 (Suppl. 1), S99-S109.

Mosmann, T., 1983. Rapid colorimetric assay for cellular growth and survival: application to proliferation and cytotoxicity assays. J. Immunol. Methods 65, 55-63.

Notka, F., Meier, G., Wagner, R., 2004. Concerted inhibitory activities of Phyllanthus amarus on HIV replication in vitro and ex vivo. Antiviral Res. 64, 93-102.

Ogata, T., Higuchi, H., Mochida, S., Matsumoto, H., Kato, A., Endo, T., Kaji, A., Kaji, H., 1992. HIV-1 reverse transcriptase inhibitor from Phyllanthus niruri. AIDS Res. Hum. Retroviruses 8, 1937-1944.

Rajcani, J., Durmanova, V., 2001. Mechanisms of replication of alpha- and betaherpesviruses and their pathogenesis. Bratisl. Lek. Listy 102, 505-514.

Reed, L.J., Muench, H., 1938. A simple method of estimating fifty per cent endpoints. Am. J. Hyg. 27, 493-497.

Stranska, R., van Loon, A.M., Polman, M., Schuurman, R., 2002. Application of real-time PCR for determination of antiviral drug susceptibility of herpes simplex virus. Antimicrob. Agents Chemother. 46, 2943-2947.

Suárez, B., Palacios, N., Fraga, N., Rodríguez, R., 2005. Liquid chromatographic method for quantifying polyphenols in ciders by direct injection. J. Chromatogr. A 1066 , 105-110.

Taylor, G.H., 2003. Cytomegalovirus. Am. Fam. Physician 67, 519-524.

Venkateswaran, P.S., Millman, I., Blumberg, B.S., 1987. Effects of an extract from Phyllanthus niruri on hepatitis $\mathrm{B}$ and woodchuck hepatitis viruses: in vitro and in vivo studies. Proc. Natl. Acad. Sci. USA 84, 274-278.

Whitley, R.J., Kimberlin, D.W., Roizman, B., 1998. Herpes simplex viruses. Clin. Infect. Dis. 26, 97-109. 